\title{
A new technique for assessing arterial pressure wave forms and central pressure with tissue Doppler Brian A Haluska*1, Leanne Jeffriess ${ }^{\dagger 1}$, Phillip M Mottram ${ }^{\dagger 1}$, Stephane G Carlier ${ }^{\dagger 2}$ and Thomas H Marwick ${ }^{\dagger 1}$
}

Address: ${ }^{1}$ University of Queensland Department of Medicine, Princess Alexandra Hospital, Ipswich Rd, Brisbane Q4102, Australia and 2The Cardiovascular Research Foundation, 55 East 59th St., 6th Fl., New York, NY 10022-1122, USA

Email: Brian A Haluska* - b.haluska@uq.edu.au; Leanne Jeffriess - l.jeffriess@uq.edu.au;

Phillip M Mottram - Philip.Mottram@southernhealth.org.au; Stephane G Carlier - scarlier@crf.org; Thomas H Marwick - t.marwick@uq.edu.au

* Corresponding author †Equal contributors

Published: 3I January 2007

Cardiovascular Ultrasound 2007, 5:6 doi:10.1 I86/1476-7|20-5-6
Received: 24 January 2007

Accepted: 31 January 2007

This article is available from: http://www.cardiovascularultrasound.com/content/5/1/6

(c) 2007 Haluska et al; licensee BioMed Central Ltd.

This is an Open Access article distributed under the terms of the Creative Commons Attribution License (http://creativecommons.org/licenses/by/2.0), which permits unrestricted use, distribution, and reproduction in any medium, provided the original work is properly cited.

\begin{abstract}
Background: Non-invasive assessment of arterial pressure wave forms using applanation tonometry of the radial or carotid arteries can be technically challenging and has not found wide clinical application. 2D imaging of the common carotid arteries is routinely used and we sought to determine whether arterial waveform measurements could be derived from tissue Doppler imaging (TDI) of the carotid artery.
\end{abstract}

Methods: We studied 91 subjects ( 52 men, age $52 \pm 14$ years) with and without cardiovascular disease. Tonometry was performed on the carotid artery simultaneously with pulsed wave Doppler of the LVOT and acquired digitally. Longitudinal 2D images of the common carotid artery with and without TDI were also acquired digitally and both TDI and tonometry were calibrated using mean and diastolic cuff pressure and analysed off line.

Results: Correlation between central pressure by TDI and tonometry was excellent for maximum pressure $(r=0.97, p<0.000 \mathrm{I})$. The mean differences between central pressures derived by TDI and tonometry were minimal (systolic $5.36 \pm 5.5 \mathrm{mmHg}$; diastolic $1.2 \pm 1.2 \mathrm{mmHg}$ ).

Conclusion: Imaging of the common carotid artery motion with tissue Doppler may permit acquisition of a waveform analogous to that from tonometry. This method may simplify estimation of central arterial pressure and calculation of total arterial compliance.

\section{Background}

Blood pressure has been shown to be a strong predictor of cardiovascular risk-increased systolic blood pressure (SBP) reflecting stiffening of the arterial walls and changes in vascular structure, and increased pulse pressure (PP) reflecting stiffening of conduit vessels [1,2]. Arterial stiffness may now be measured as a marker of arterial health [3], and in combination with cardiac output can be used to calculate total arterial compliance. This is usually performed using applanation tonometry of the radial artery and the use of a transfer function to estimate central pressure, but there are potential problems imposed by the transfer function [4-6] and direct acquisition of a central waveform might avoid them. However, acquisition of arterial waveforms obtained by applanation tonometry assumes that the artery is compressible [5,7], which may 
not be true for the carotid artery. Moreover, the adoption of this technique has been adversely impacted by lack of familiarity with tonometry and the need to obtain specialized equipment.

In contrast, carotid imaging is very familiar. Assessment of carotid intima-media thickness (IMT) is well established $[8,9]$, has been used as a marker of atherosclerotic burden, and has prognostic value [10]. The use of the same imaging test to obtain arterial waveforms could enhance the anatomic evaluation of carotid IMT with information about arterial function. Doppler echocardiography, used traditionally to evaluate the velocity and direction of blood flow in the heart and vessels, can be used to evaluate low velocity, high amplitude signals which come from tissue by reduction of the wall filters and scale $[11,12]$. The use of color tissue Doppler imaging (TDI) permits rapid, simultaneous visualization of multiple structures in a single view. To date, the main cardiovascular application of this technique has been in myocardial tissue characterization [13]. In this study, we sought whether assessment of central pressure using displacement measured by TDI correlated with measures attained by applanation tonometry, and could be useful in assessing patients at risk for cardiovascular disease.

\section{Methods}

\section{Patient selection}

We studied 91 subjects (52 men, age $52 \pm 14$ years) with and without cardiovascular disease. Of these patients, 33 were normal controls (NL), 28 were patients with isolated systolic hypertension (HTN), 10 were normotensive patients with diabetes mellitus (DM), 10 were patients with systolic heart failure (CHF), and 10 were patients who had undergone renal transplantation (RT). Clinical data, blood pressure, and cardiovascular risk factors were gathered and all patients were then studied with simultaneous applanation tonometry and pulsed-wave Doppler and then had 2D ultrasound and tissue Doppler performed on their carotid artery.

\section{Applanation tonometry}

Applanation tonometry was performed on the right carotid artery in all patients after they had been allowed to rest for 5-10 minutes. Tonometry uses a transcutaneously applied, micro-manometer-tipped probe which is placed against an arterial wall. Application of sufficient pressure to distort, or applanate the artery creates a signal which approximates instantaneous arterial pressure (Figure 1). This is then digitized and reconstructed on a personal computer. Blood pressure was measured using a standard sphygmomanometer on the right brachial artery, after the patient was allowed to rest 5-10 minutes. Calibration of the tonometric waveform was performed by assuming equivalence of mean $[(2 * \mathrm{DBP}+\mathrm{SBP}) / 3]$ and diastolic brachial cuff pressure.

\section{Calculation of arterial compliance}

Total arterial compliance (TAC) was derived using the pulse pressure method, using a combination of stroke vol-
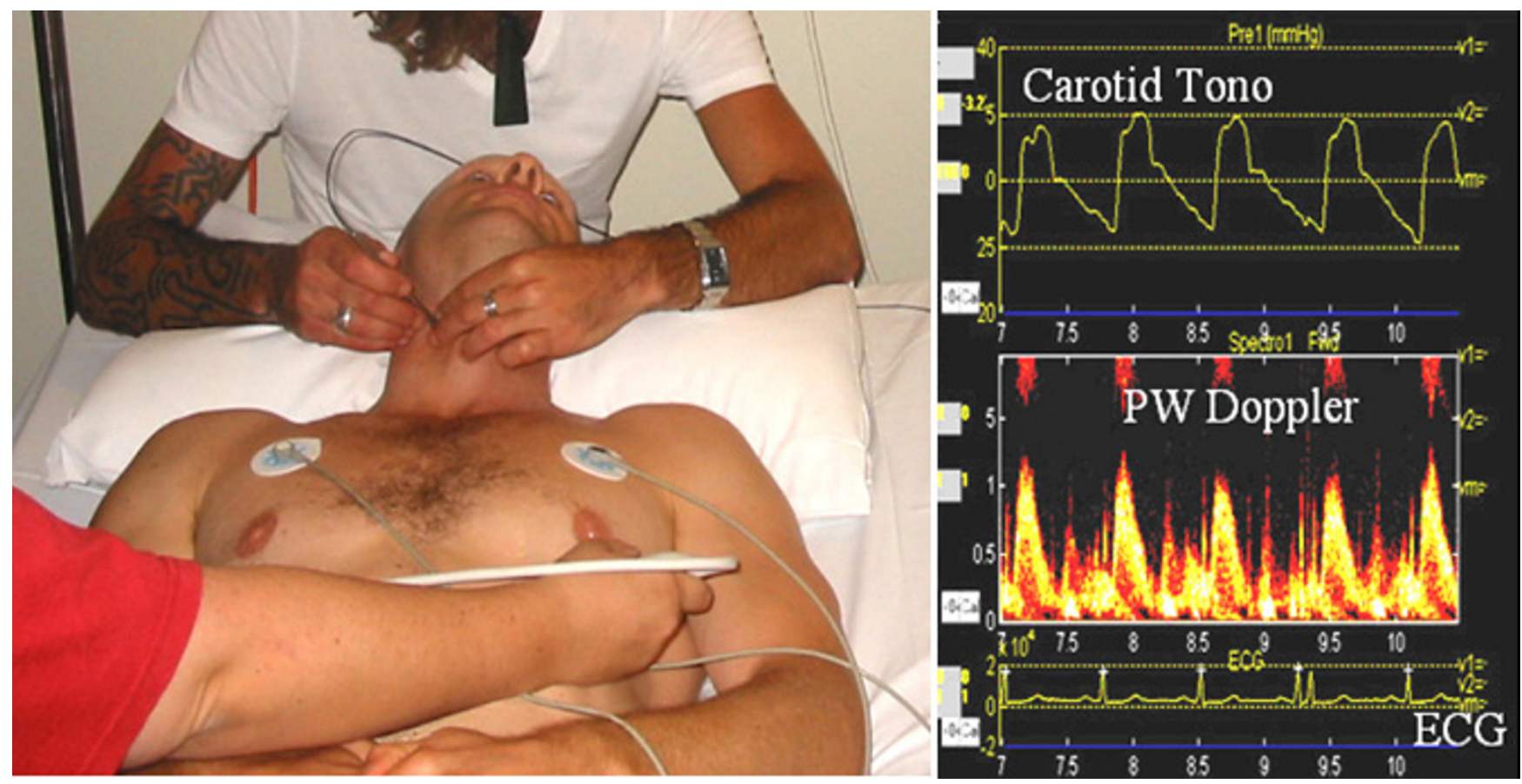

Figure I

Acquisition of carotid tonometry and pulsed Doppler. Acquisition of simultaneous carotid tonometry and pulsed Doppler of the LVOT (left) and digitized raw data (right) showing carotid tonometry, reconstructed pulsed-wave Doppler and ECG. 
ume (derived by echocardiography from the dimensions and pulsed-wave Doppler measurement of flow in the left ventricular outflow tract (LVOT)) and the pressure waveform obtained from applanation tonometry of the radial artery [14]. These waveforms were obtained simultaneously with the pulsed-wave Doppler, digitized (WaveBook 512, IOTech Inc., Cleveland, $\mathrm{OH}$ ), and transferred to a laptop computer, where they were synchronized using the $\mathrm{R}$ wave of the electrocardiogram. Using specialized acquisition software, three sets of gated data (ECG, tonometry, Doppler) were acquired and stored for off-line analysis (figure 1). Depending on heart rate, this was usually 20-30 cardiac cycles per patient. Echocardiographic images and pulsed Doppler were acquired using a Philips HDI5000 ultrasound system (Philips Inc, Bothell, WA) with a $1.7 \mathrm{MHz}$ harmonic imaging probe.

\section{Derivation of TAC}

For calculation of total arterial compliance, the binary files were processed and analyzed using a custom analysis program written in MatLab 4. Between five and ten cardiac cycles of tonometry and Doppler were chosen from the raw dataset based on data quality and averaged for analysis. With the use of cursors to identify the beginning and end of aortic ejection, peak ejection, and peak pulse pressure on both the reconstructed Doppler and central pressure waveforms, the analysis program determined mean values for pressure and flow and calculated a mean aortic pressure (figure 2). Based on the pressure and flow data derived from the central pressure waveform and the Doppler, the analysis program generated values for total arterial compliance, augmentation index, and other hemodynamic indices. We have previously reported the intra-observer variation (mean TAC $1.17 \pm 0.02 \mathrm{ml} /$ $\mathrm{mmHg}$ ) and coefficient of variation of this method $(1.7 \%)[15]$.

\section{Carotid TDI}

The carotid arteries were scanned longitudinally in the anterior, lateral and posterior aspects $2-10 \mathrm{~cm}$ below the bifurcation, and digital cine loops are acquired for offline analysis. The image was then optimized for TDI using the smallest possible region of interest (ROI) box to achieve the highest frame rate, which was usually between 160220 frames per second. The 2D and color Doppler settings were also customized for extraction of vessel displacement: for 2D imaging - dynamic range of $150 \mathrm{~dB}$, the 2D option is set to penetration, persistence is set at low and frame rate is set at maximum; for the color tissue Doppler - the gain was set at $100 \%$, with a PRF of $>200 \mathrm{~Hz}$. Care was taken not to include any discrete plaques in the tissue Doppler measurements. Loops of 3-5 cardiac cycles with TDI were then acquired digitally for offline analysis (figure 3).

\section{Derivation of vessel wall displacement}

The TDI images were analyzed offline using custom-written software (AWM v1.05, Philips Medical Systems, Bothell, WA) which extracts the velocity information for the ROI area over the cardiac cycle, and with a processing algorithm, generates values for vessel wall displacement (in microns) over time [16]. These data were then saved and exported in numerical format for analysis (figure 4).

\section{Comparison of TDI displacement and tonometry}

Both the extracted TDI displacement curves and the tonometric curves were then imported into a custom written MatLab program for analysis and once calibrated, a comparison was done between the waveforms (figure 5). Carotid displacement curves (in $\mu \mathrm{m}$ ) derived from the TDI recordings were transformed into approximated pulse pressure curves (in $\mathrm{mmHg}$ ) following the methodology described by Van Bortel et al based on the observation that the mean blood pressure is constant throughout the large artery tree [17], as well as the diastolic pressure [18]. The tonometric recordings were calibrated setting the average integrated curve equal to the mean blood pressure [derived from $(2 * \mathrm{DBP}+\mathrm{SBP}) / 3$ ] or if used, from an average automatic BP recording system. The minimum diastolic tonometric value was set equal to the diastolic BP. Similarly, a two-point calibration was used for the carotid distension curves, integrated with the mean set to the mean $\mathrm{BP}$, and the minimum distension set to the diastolic $\mathrm{BP}$.

\section{Statistical analysis}

Pearson's correlation was used to determine the concordance between central pressure determined by TDI and by tonometry, paired t-tests were used to determine the mean differences between the two techniques and Bland-Altman analysis was used to determine the differences from the mean for central pressure between the two techniques.

\section{Results \\ Patient characteristics}

Table 1 shows clinical data, medications, blood pressure, flow and compliance for the whole patient group. Patients had an average of $1 \pm 1$ cardiovascular risk factors, and were on $1 \pm 1$ antihypertensive medications. However, blood pressure, cardiac output and TAC were all within the normal range.

\section{Comparison of central pressures obtained by tonometry and tissue Doppler imaging}

Correlation between central pressure by TDI and tonometry was excellent for maximum pressure $(r=0.97$, $p<$ $0.0001)$. In paired t-tests the mean differences between central pressures derived by the two techniques was minimal, although there was a $5 \mathrm{mmHg}$ difference between maximum pressure derived by TDI and tonometry (table 2). Bland-Altman analysis was then performed to deter- 


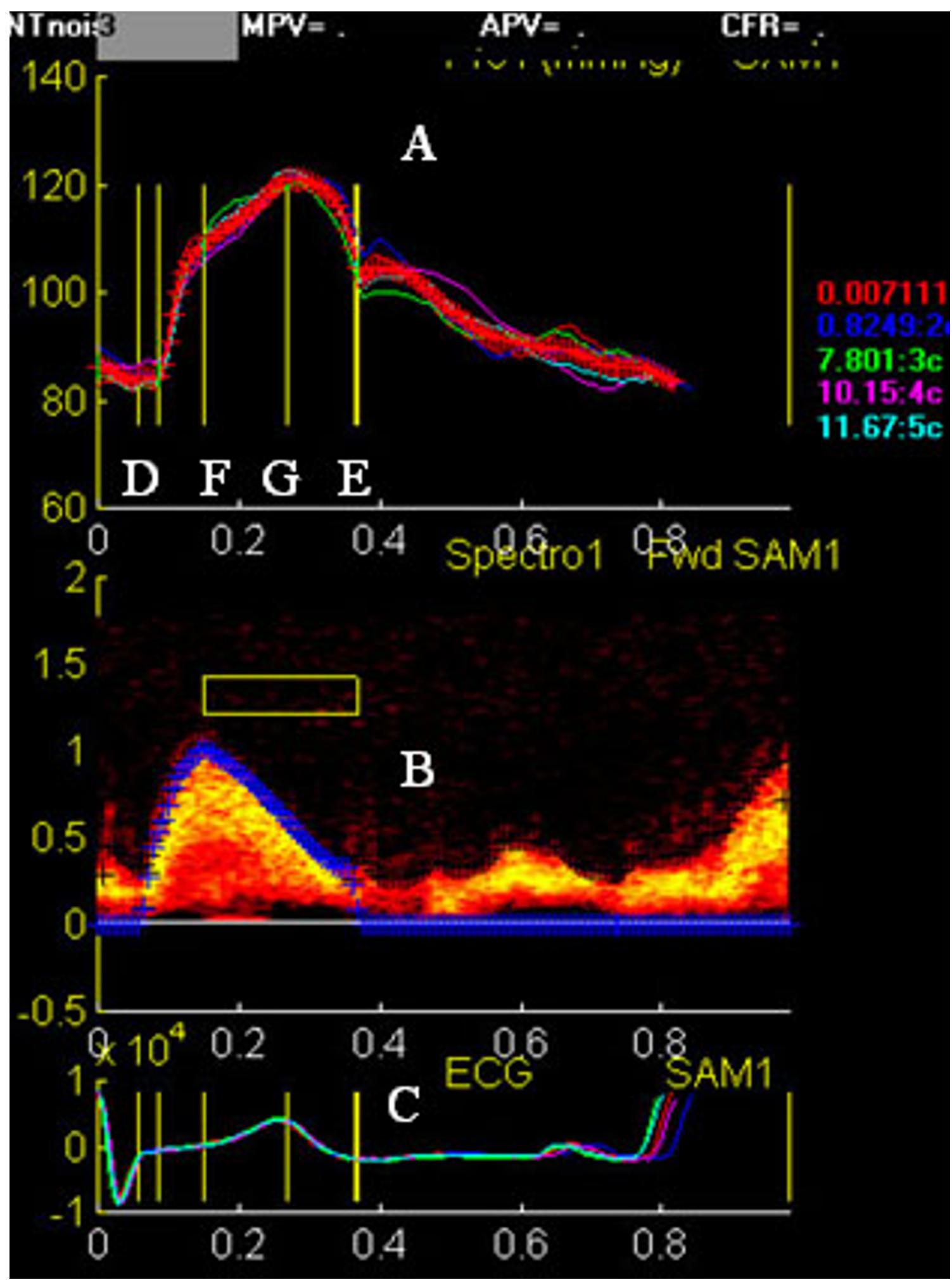

\section{Figure 2}

SAM analysis window. Analysis window for estimating total arterial compliance showing (A) averaged and calibrated carotid pressure waveform, (B) averaged reconstructed pulse-wave Doppler of the left ventricular outflow and (C) ECG. Cursors mark beginning $(D)$ and end aortic ejection $(E)$, peak aortic ejection $(F)$ and peak pulse pressure $(G)$. 

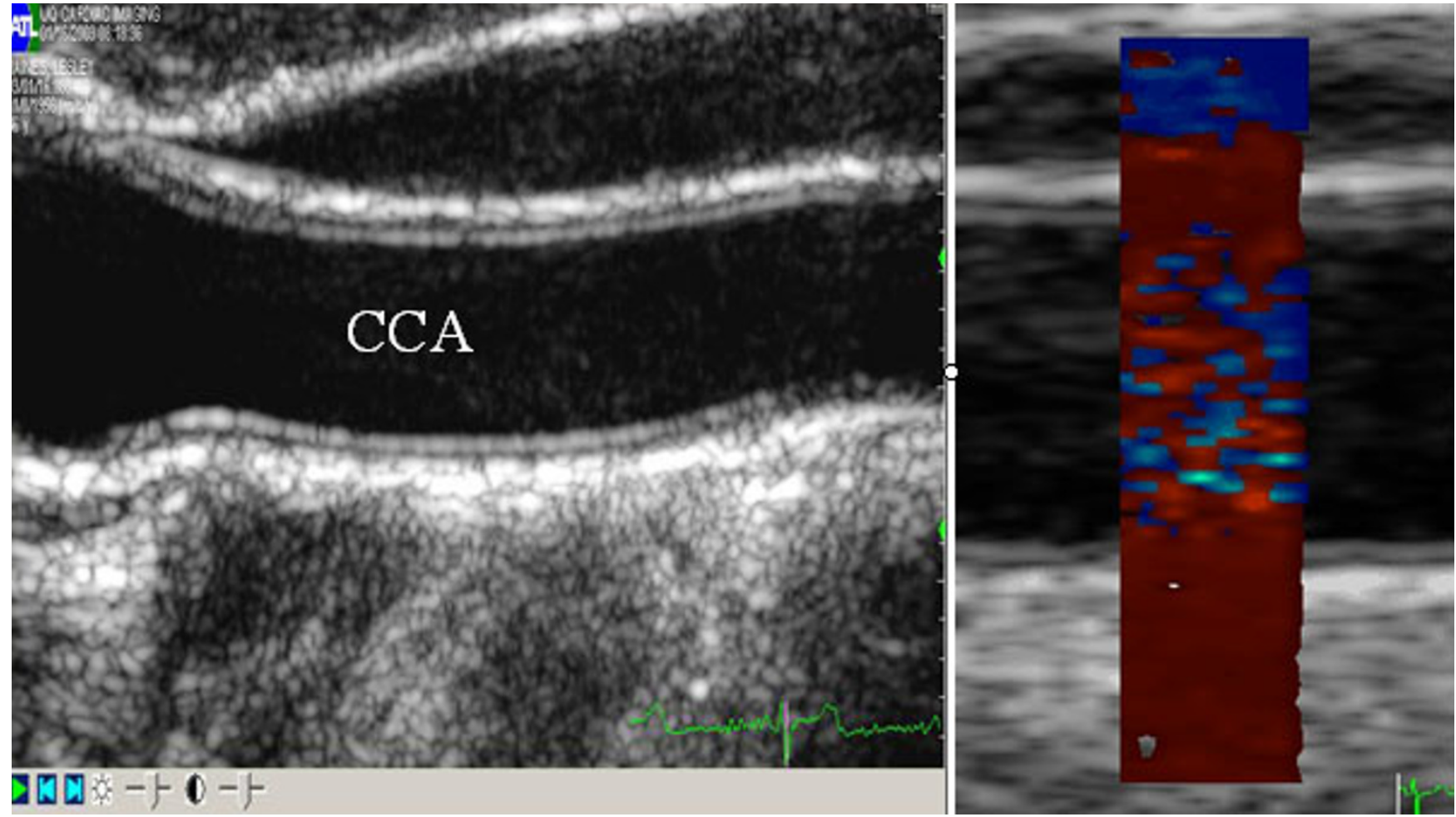

Figure 3

Carotid 2D and TDI imaging. Digitized longitudinal 2D scan of the common carotid artery (CCA) just prior to the bifurcation (right) and optimized ROI window with color tissue Doppler of the CCA.

mine the concordance between the two techniques. For diastolic pressure the differences were negligible $(1.20 \pm$ $1.2 \mathrm{mmHg}$ ) but this was expected since both sets of data were calibrated with diastolic cuff pressure (figure 6). For systolic pressure however the difference from the mean was greater $(5.36 \pm 5.5 \mathrm{mmHg})$ with the TDI underestimating maximum pressure (figure 6 ).

\section{Comparison of maximum pressure in subgroups}

Because of the calibration with mean and diastolic pressure, only maximum pressure was compared in a subgroup analysis. The HTN group had the highest maximum pressure and the CHF patients had the lowest pressure, as would be expected. The controls, DM group and RT groups all had maximum pressure within a normal range. In paired t-tests comparing the TDI and tonometry the HTN group had the highest paired difference $(9 \pm 6$ mmHg; $\mathrm{p}<0.0001)$ and the controls had the smallest paired difference $(2 \pm 2 \mathrm{mmHg} ; \mathrm{p}<0.0001)$ (table 3$)$.

\section{Technical limitations of TDI approach}

The TDI technique underestimated systolic pressure in about a third of cases resulting in a higher than acceptable difference in the Bland-Altman analysis. The causes of this appear to be related to inappropriate TDI settings and other technical problems, and therefore this may be avoided with experience and guidelines. Failure to use a sufficiently high pulse repetition frequency caused aliasing of the velocity signals and the resulting displacement waveforms and calibration by the technique described above produced a pressure waveform which does not reflect accurate maximum pressure when compared to the carotid tonometry in several cases (Figure 7). Excessive motion of the carotid artery may lead to failure of the edge detection mechanism. This excessive motion has affected the reproducibility of carotid tonometry in other studies and can be seen here as well (Figure 7) and may be controlled by a simple breath hold or transducer immobilization. Other causes of failure of the edge detection with TDI are reverberation artifacts, excessive noise in the vessel lumen and excessive vessel movement due to breathing or high mobility of the carotid artery (Figure 8). Once again these may be able to be corrected with breath holds, patient positioning, and careful attention to 2D and Doppler settings. Thus, with attention to technical aspects and patient preparation this technique is likely to be highly feasible.

\section{Discussion}

The results of this study suggest that carotid TDI can be used to approximate central blood pressure and that the resulting waveform is analogous to that obtained with 


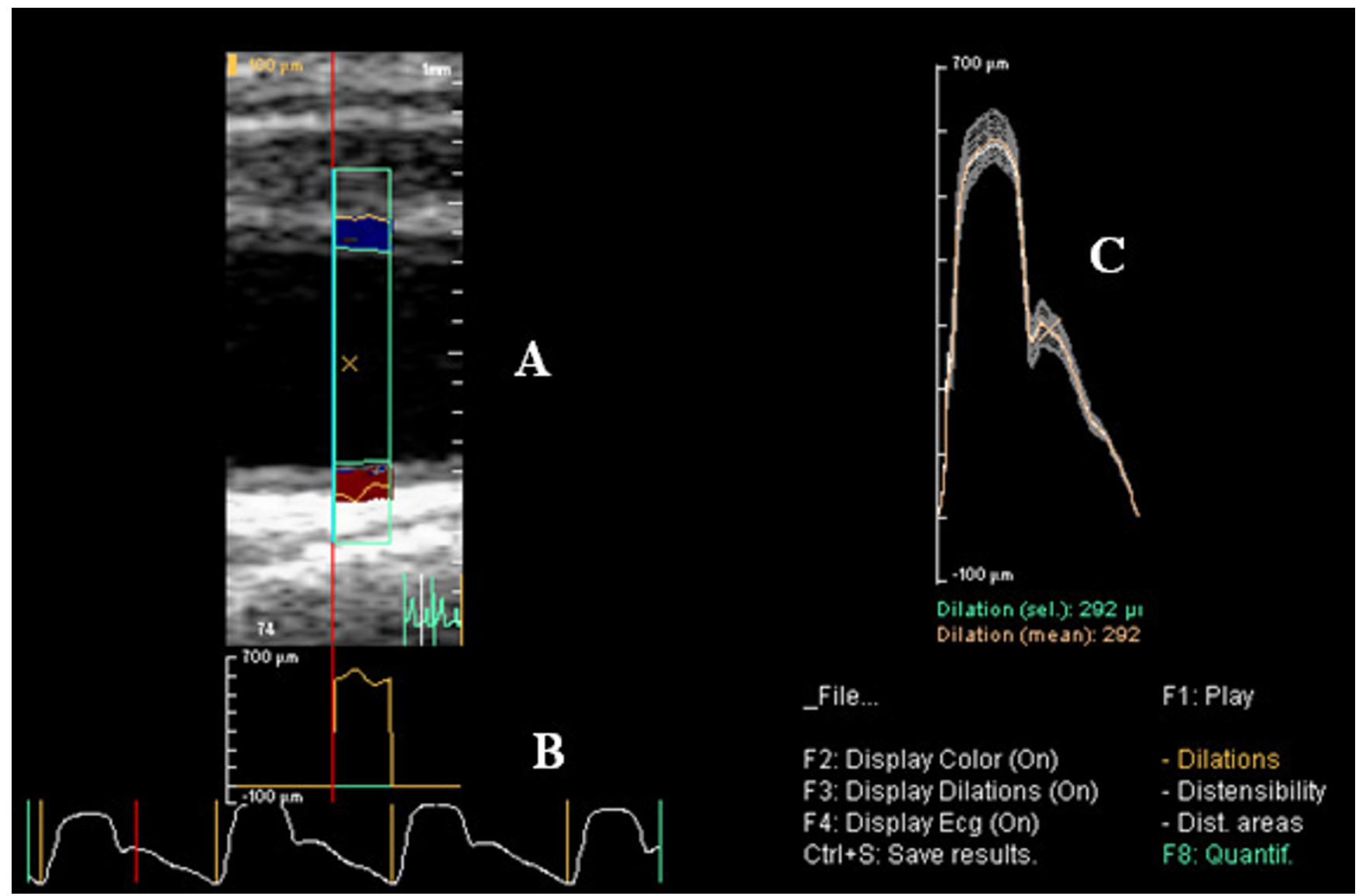

Figure 4

Arterial wall motion (AWM) analysis window. Arterial wall motion analysis window showing (A) the extracted arterial displacement over the cardiac cycle, $(B)$ individual displacement curves over time for each cardiac cycle, and (C) the mean displacement for all of the cardiac cycles.

applanation tonometry. This would obviate the need for a transfer function and the waveform could be used to calculate total arterial compliance from central rather than peripheral pressure. The advantage of TDI imaging is that vascular imaging is available, feasible in a clinical setting, and can be incorporated into any cardiovascular imaging examination without extra equipment.

\section{Significance of arterial properties}

Total arterial compliance is reduced with age, vascular disease and hypertension [19-21], and is linked with the sequellae of these disorders. Reduction of compliance leads to an increase in afterload on the heart, an increase in pulse pressure and in turn, left ventricular hypertrophy [22] and diastolic dysfunction. Increased pulse pressure is a determinant of cardiovascular risk and mortality $[2,23$ 25]. Lower compliance also leads to lower diastolic pressure [26], resulting in a decreased coronary perfusion pressure [27]. Several studies have shown a correlation between compliance and the presence of significant CAD [28-30] as might well be expected due to common cardiovascular risk factors. Moreover, arterial compliance has been shown to be a contributor to the provocation of ischemia at stress testing [31], and an association has been documented between reduced exercise capacity and the presence of a lower ischemic threshold [32,33].

While brachial blood pressure has been shown to be a strong predictor of cardiovascular morbidity, mortality and outcome $[2,22,34,35]$ the role of central pressure in clinical outcomes is increasingly recognized [35]. Independent of brachial blood pressure, central pulse pressure predicts left ventricular structure [36,37] and the extent of coronary artery disease. The CAFÉ substudy of the ASCOT trial showed that central pressure and pressure augmentation were significantly associated with clinical endpoints [35]. Despite insignificant differences between brachial pressures in the study groups over a four year follow-up 


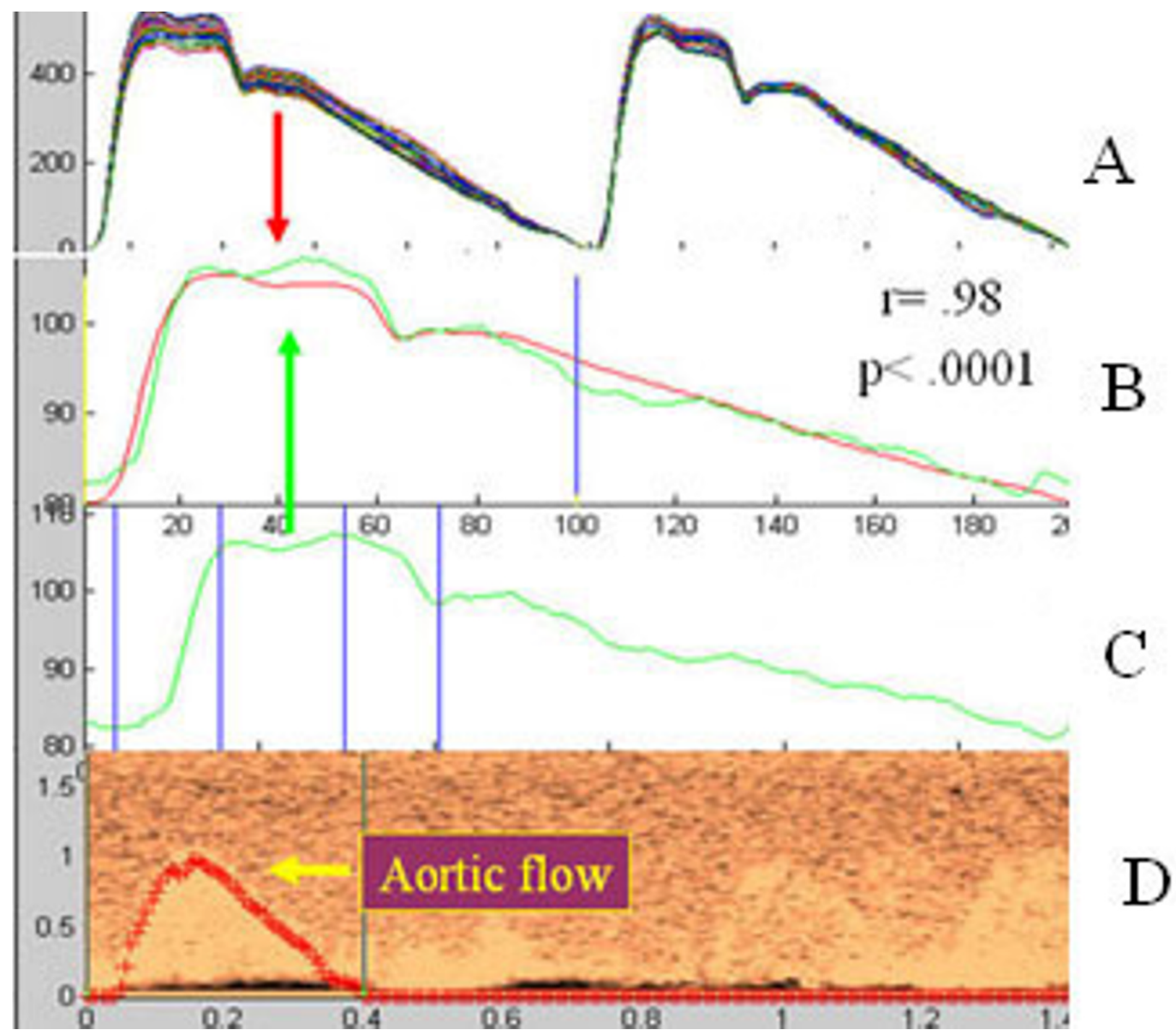

Figure 5

SAMTDI analysis window. Analysis window for comparison of tonometry and TDI showing (A) the extracted raw TDI displacement curves, (C) carotid tonometry arterial waveform, (B) calibrated TDI waveform (red) and carotid arterial waveform (green), and (D) reconstructed Doppler of aortic flow.

Table I: Patient characteristics

$n=91$

\begin{tabular}{cccc}
\hline Male Gender & $52(57 \%)$ & Age & $52 \pm 14$ \\
Smoking & $20(22 \%)$ & SBP (mmHg) & $124 \pm 22$ \\
Hypertensive & $46(50 \%)$ & DBP (mmHg) & $76 \pm 10$ \\
DM & $15(16 \%)$ & MAP (mmHg) & $92 \pm 13$ \\
Lipids & $30(33 \%)$ & PP (mmHg) & $47 \pm 18$ \\
$\beta$ Blocker & $20(22 \%)$ & CO (L/min) & $4.6 \pm 1.32$ \\
CA Blocker & $15(16 \%)$ & TAC (ml/mmHg) & $1.48 \pm .70$ \\
ACE & $26(28 \%)$ & \# risk factors & $1 \pm 1.2$ \\
Statin & $29(32 \%)$ & \# medications & $1 \pm 1.2$ \\
\hline
\end{tabular}

Clinical characteristics, medications, Systolic, diastolic, mean arterial and pulse blood pressure (SBP, DBP, MAP, PP), cardiac output (CO) and total arterial compliance (TAC). 
Table 2: Correlations and t-tests

\begin{tabular}{lcccr}
\hline & Tono & TDI & r & Difference \\
\hline Maximum BP-mmHg & $112 \pm 20$ & $107 \pm 17$ & .97 & $5.36 \pm 5.5$ \\
Minimum BP-mmHg & $77 \pm 11$ & $75 \pm 10$ & .99 & $1.20 \pm 1.2$ \\
Mean BP-mmHg & $92 \pm 13$ & $92 \pm 13$ & 1.00 & $-.01 \pm .06$ \\
Median BP-mmHg & $89 \pm 12$ & $92 \pm 13$ & .98 & $-2.96 \pm 2.52$ \\
\hline
\end{tabular}

Results of paired t-tests and Pearson's correlations between TDI and tonometry in the subgroups for maximum, minimum, mean and median blood pressure. Tono - tonometry; BP - blood pressure.
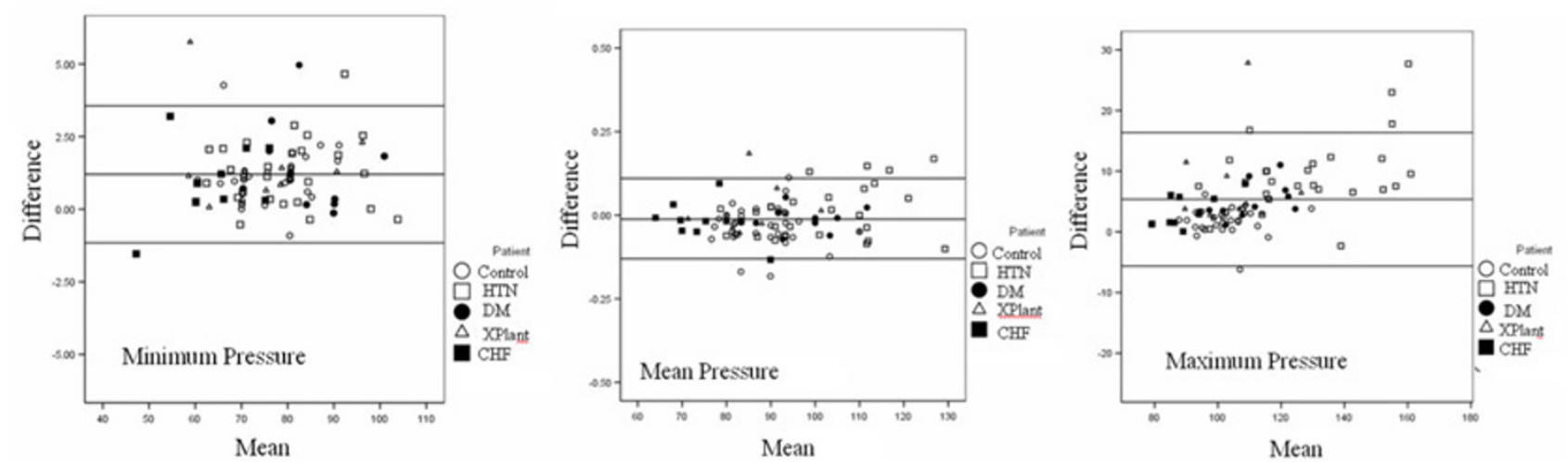

\section{Figure 6}

Comparison of minimum, mean and maximum pressure. Bland-Altman plots comparing mean pressure versus the difference in mean pressure for minimum, mean and maximum pressure.

Table 3: Correlations and t-tests

\begin{tabular}{lcccc}
\hline & Tono $(\mathrm{mmHg})$ & TDI $(\mathrm{mmHg})$ & Difference $(\mathrm{mmHg})$ & $\mathrm{P}$ \\
\hline Control (33) & $103 \pm 9$ & $101 \pm 9$ & $2.08 \pm 2.2$ & $<.0001$ \\
HTN (28) & $132 \pm 22$ & $122 \pm 19$ & $9.23 \pm 6.3$ & $<.0001$ \\
DM (10) & $114 \pm 10$ & $109 \pm 9$ & $5.18 \pm 3.0$ & $<.0001$ \\
RT (10) & $108 \pm 12$ & $100 \pm 11$ & $7.50 \pm 7.7$ & $<.01$ \\
CHF (10) & $91 \pm 10$ & $87 \pm 8$ & $3.38 \pm 2.6$ & $<.003$ \\
\end{tabular}

Subgroup analysis and paired differences between carotid tonometry and tissue Doppler. Tono - tonometry 


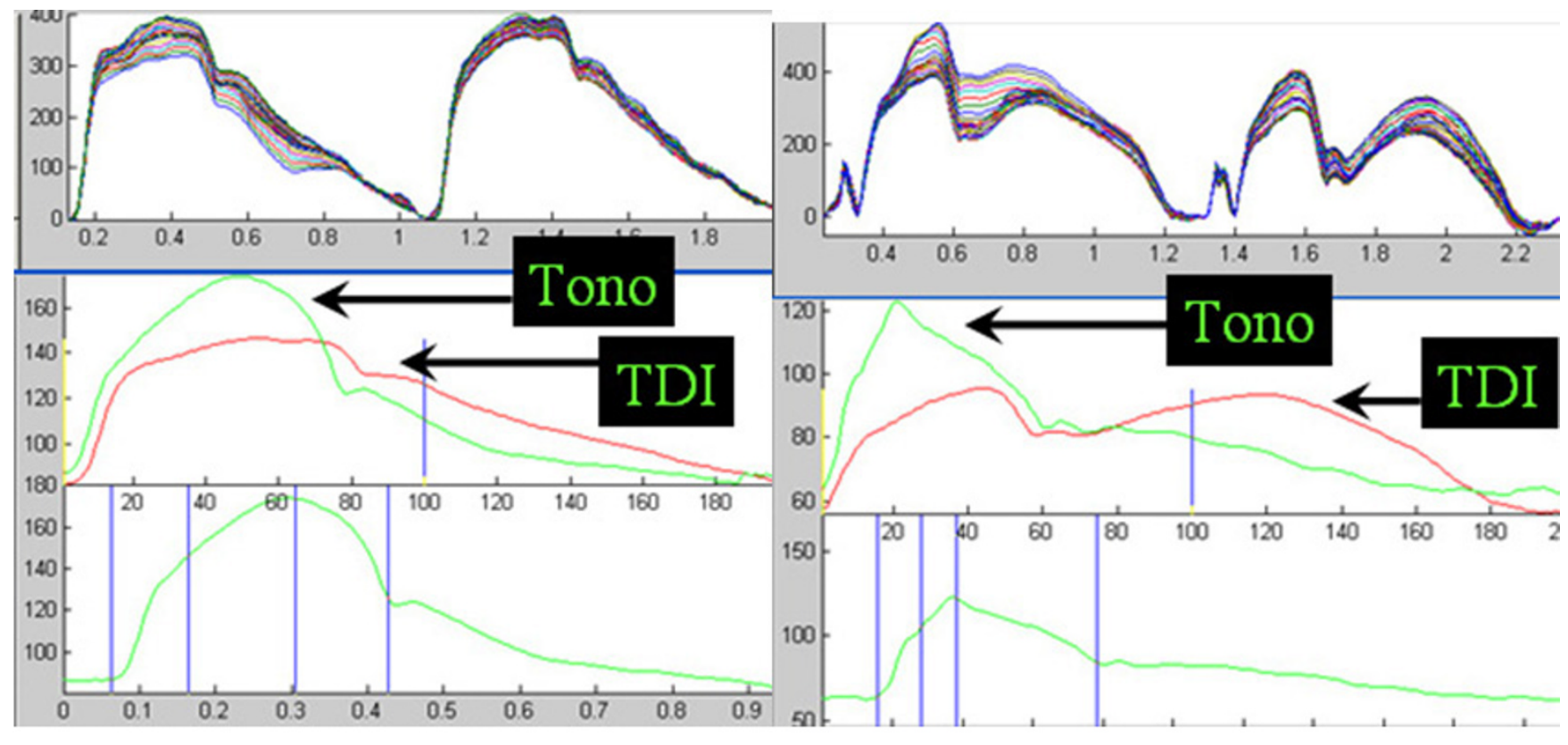

A

Figure 7

Limitations - discordance. Two examples of discordance in the comparison of central pressure obtained by tonometry and TDI. (A) Shows a patient in which the TDI velocities were aliased resulting in a gross underestimation of maximum (systolic) pressure. (B) Shows a patient with excessive movement of the carotid artery during acquisition of the TDI images resulting in artifact in the displacement waveform.

period, the group with lower central pulse pressure showed a significant decrease in cardiovascular events. From the results of this study, assessment of central blood pressure appears to be paramount in the treatment of patients at risk for cardiovascular disease.

\section{Limitations of applanation tonometry}

While applanation tonometry is considered the "gold standard" for use in assessing arterial stiffness it is not without limitations. The major limitation of pressure measurement with tonometry is the use of brachial cuff pressure to calibrate the signals. Past studies have shown poor inter-observer variability in taking brachial pressure and a poor correlation between reported and actual pressure [38,39]. Operator error and a learning curve with acquisition of tonometry also play a role in its usefulness as a clinical tool. And while several studies have shown the limitations of using transfer functions with radial tonometry $\{4,5,6,7,14\}$, the issues of performing carotid tonometry remain-lack of bony support underneath to achieve true applanation, obesity, respiratory changes and mobility of the artery

\section{Conclusion}

The results of this study suggest that tissue Doppler may be useful in assessing central arterial pressure and in the estimation of total arterial compliance. Carotid imaging for IMT is familiar and feasible and has already been incorporated into many cardiovascular imaging laboratories. The use of the same imaging test to obtain arterial waveforms could enhance the evaluation of carotid IMT with information about arterial function as well. In addition, calibration of the arterial displacement waveforms obtained from TDI may simplify the estimation of total arterial compliance and alleviate the technical considerations of tonometry.

\section{Competing interests}

The author(s) declare that they have no competing interests.

\section{Authors' contributions}

$\mathrm{BAH}$ conceived the study design, gathered and analyzed the data, interpreted the results and drafted the manuscript 


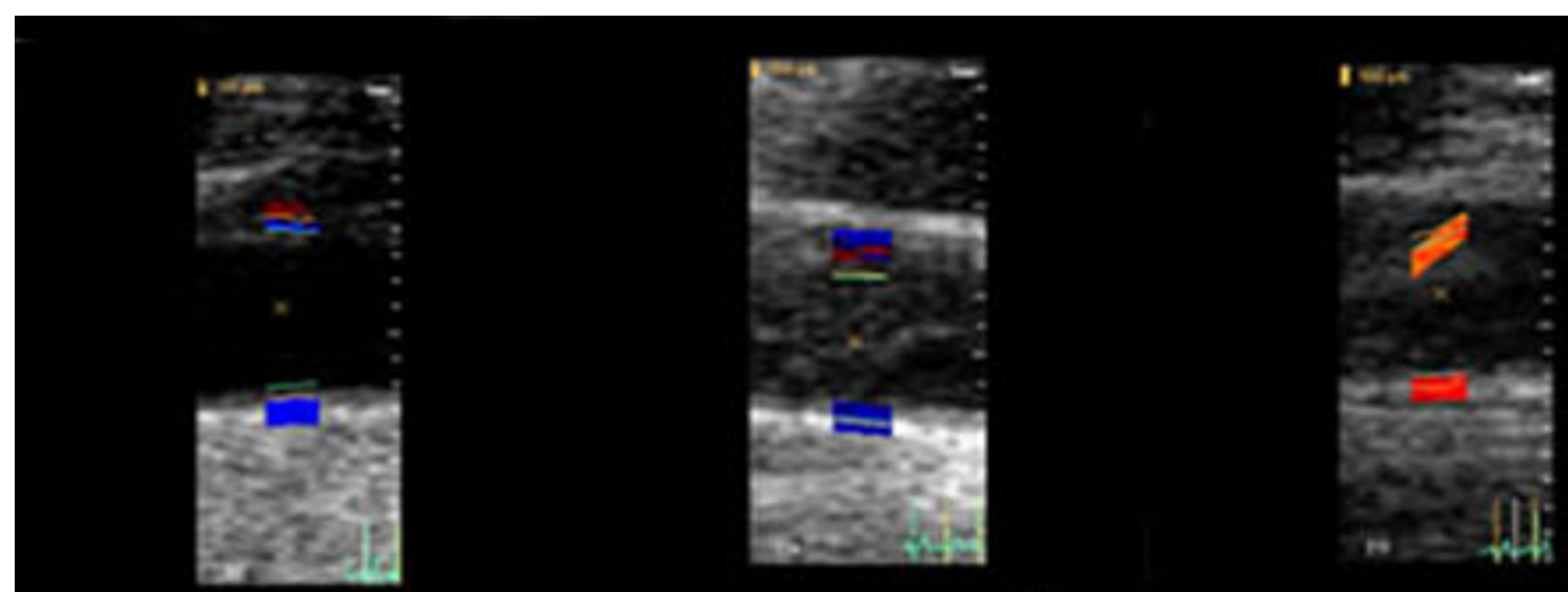

A $\quad$ B $\quad$ C
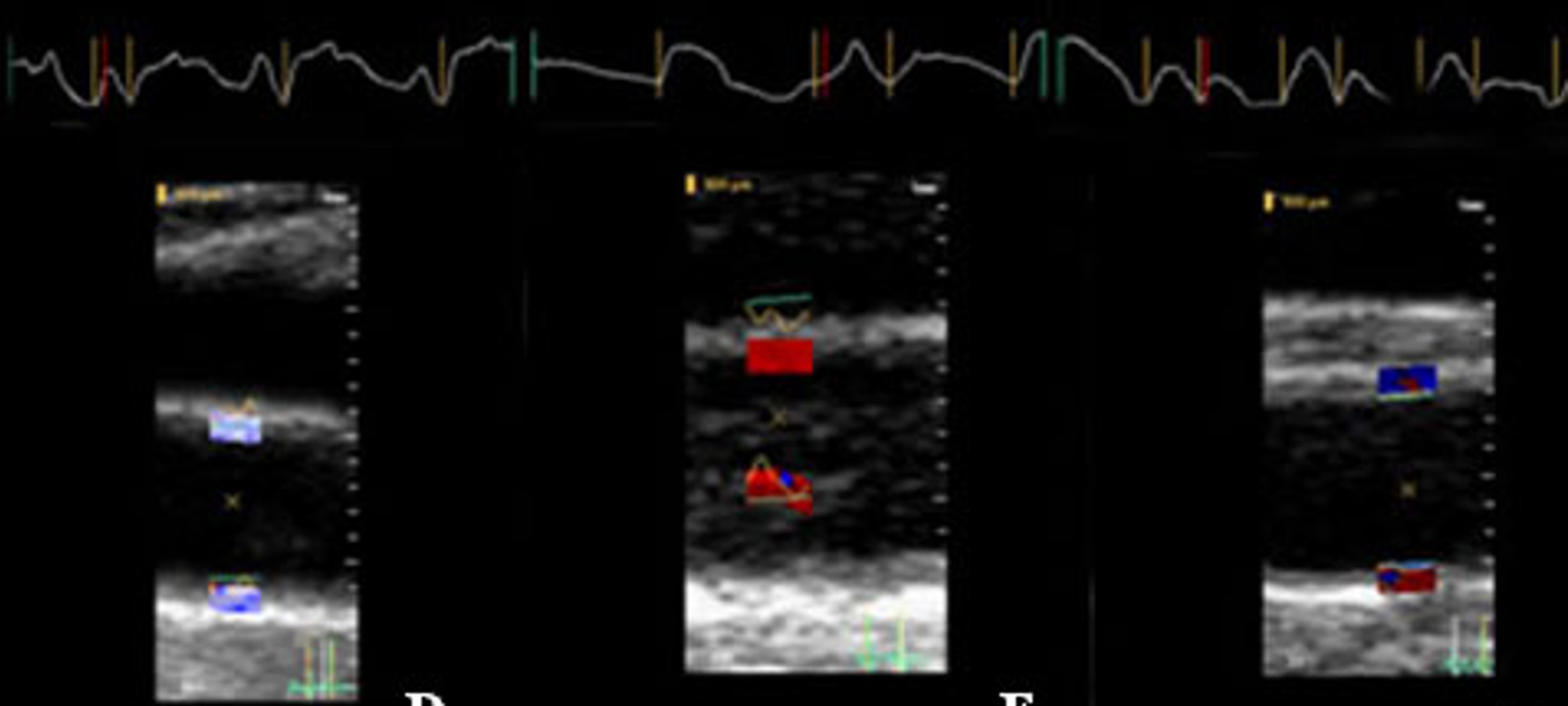

D

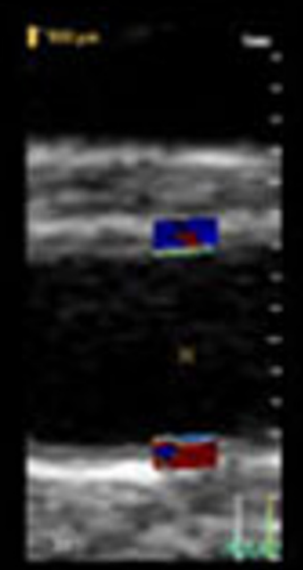

$\mathbf{E}$

$\mathbf{F}$

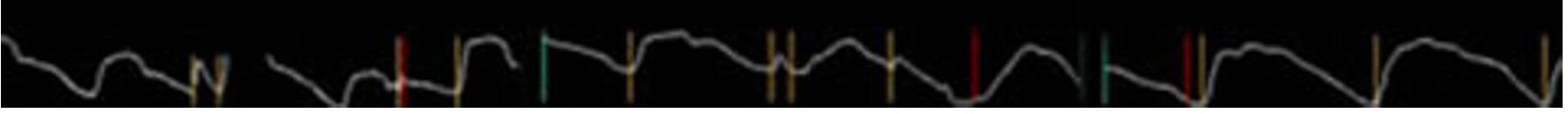

\section{Figure 8}

Limitations - artifacts. Artifacts with carotid tissue Doppler caused by technical issues: A - artifact from breathing which caused the artery to move in and out of the image plane; B - Excessive noise in the lumen which the analysis program picked up as tissue; $C$ - Reverberation causing inaccurate detection of the vessel wall; $D$ - Excessive movement of the artery during the cardiac cycle; $E$ - Reverberation causing inaccurate detection of the vessel wall; F - Very little movement detected in the artery at peak pulse pressure and flow resulting in poor quality waveforms. 
LJ assisted in gathering the tonometry and TDI data

PMM assisted in gathering the carotid tonometry and in recruiting patients for the study.

SGC developed the acquisition and analysis software for the tonometry and wrote the analysis program to compare the tonometry and TDI

THM was instrumental in study design and implementation, helped to interpret the results and edited the final manuscript

\section{Acknowledgements}

Authors would like to acknowledge $\mathrm{Dr}$ Tine de Backer for help in acquiring carotid tonometry. The study was made possible by a grant from the National Health and Medical Research Council of Australia

\section{References}

I. Cameron JD, Gatzka CD, Kingwell BA: Assessment of large artery function. Coron Artery Dis 2002, 13:405-13.

2. Sesso HD, Stampfer MJ, Rosner B, Hennekens CH, Gaziano JM, Manson JE, Glynn RJ: Systolic and diastolic blood pressure, pulse pressure, and mean arterial pressure as predictors of cardiovascular disease risk in Men. Hypertension 2000, 36:80I-7.

3. O'Rourke MF, Staessen JA, Vlachopoulos C, Duprez D, Plante GE: Clinical applications of arterial stiffness; definitions and reference values. Am J Hypertens 2002, I 5:426-44.

4. Hope SA, Tay DB, Meredith IT, Cameron JD: Use of arterial transfer functions for the derivation of aortic waveform characteristics. J Hypertens 2003, 21:1299-305.

5. Segers P, Carlier SG, Pasquet A, Pabben SI, Hellevik R, Remme E, De Backer T, De Sutter J, Thomas JD, Verdonck P: Individualizing the aorto-radial pressure transfer function: feasibility of a modelbased approach. Am J Physiol Heart Circ Physiol 2000, 279:H542-49.

6. Soderstrom S, Nyberg G, O'Rourke MF, Sellgren J, Ponten J: Can a clinically useful aortic pressure wave be derived from a radial pressure wave? $\mathrm{Br}$ / Anaesth 2002, 88:48I-8.

7. Chen $\mathrm{CH}$, Nevo E, Fetics B, Pak PH, Yin FC, Maughan WL, Kass DA Estimation of central aortic pressure waveform by mathematical transformation of radial tonometry pressure. Validation of generalized transfer function. Circulation 1997, 95: I827-36.

8. Grobbee DE, Bots ML: Carotid intima-media thickness as an indicator of generalized atherosclerosis. Jour Int Med 1994, 236:567-73.

9. Bots M, Hoes A, Koudstaal P, Hofman A, Grobbee DE: Common carotid intima-media thickness and risk of stroke and myocardial infarction: The Rotterdam study. Circulation 1997, 96:|432-37.

10. Fathi R, Marwick TH: Non-invasive tests of vascular function and structure: why and how to perform them. Am Heart J 200I, 1 41:694-703.

II. Donovan CL, Armstrong WF, Bach DS: Quantitative Doppler tissue imaging of the left ventricular myocardium: validation in normal subjects. Am Heart ] 1995, I 30:100-4.

12. Miyatake K Yamagishi M, Tanaka N Uematsu M, Yamazaki N, Mine $Y$, Sanyo A, Hirama M: New method for evaluating left ventricular wall motion by color-coded tissue Doppler imaging: in vitro and in vivo studies. I Am Coll Cardiol 1995, 25:717-24

13. Fang ZY, Yuda S, Anderson V, Short L, Case C, Marwick TH: Echocardiographic detection of early diabetic myocardial disease. J Am Coll Cardiol 2003, 41:61 I-7.

14. Carlier S, Segers P, Pasqet A, Armstrong G, Greenberg NL, Stergiopulos $\mathrm{N}$, Marwick T, Thomas JD: Non-invasive characterization of total arterial compliance by simultaneous acquisition of pressure and flow: advantages of the pulse pressure method. Computers in Cardiology 1998, 25:665-68.

15. Mottram PM, Haluska BA, Leano R, Carlier S, Case C, Marwick TH: Relation of arterial stiffness to diastolic dysfunction in hypertensive heart disease. Heart 2005, 91:I55|-6.

16. Ramnarine KV, Hartshorne T, Sensier Y, Naylor M, Walker J, Naylor AR, Panerai RB, Evans DH: Tissue Doppler imaging of carotid plaque wall motion: a pilot study. Cardiovasc Ultrasound 2003, I:I7.

17. Van Bortel LM, Balkestein EJ, van der Heijden-Spek JJ, Vanmolkot FH, Staessen JA, Kragten JA, Vredeveld JW, Safar ME, Struijker Boudier HA, Hoeks JP: Non-invasive assessment of local arterial pulse pres- sure: comparison of applanation tonometry and echo-tracking. J Hypertens 2001, 1 9: 1037-44.

18. Nichols WW, O'Rourke M: McDonald's blood flow in arteries. Theoretical, experimental and clinical principles. 4th edition. London: Arnold; 1998:453-476.

19. London GM, Pannier B, Guerin AP, Marchais SJ, Safar ME, Cuche JL: Cardiac hypertrophy, aortic compliance, peripheral resistance, and wave reflection in end-stage renal disease. Comparative effects of ACE inhibition and calcium channel blockade. Circulation 1994, 90:2786-96.

20. McVeigh GE, Bratteli CW, Morgan DJ, Alinder CM, Glasser SP, Finkelstein SM, Cohn JN: Age-related abnormalities in arterial compliance identified by pressure pulse contour analysis: aging and arterial compliance. Hypertension 1999, 33:|392-8.

21. Safar ME, London GM: Arterial and venous compliance in sustained essential hypertension. Hypertension 1987, 1 0:133-139.

22. Rajkumar C, Cameron JD, Christophidis N, Jennings GL, Dart AM: Reduced systemic arterial compliance is associated with left ventricular hypertrophy and diastolic dysfunction in older people. Am Geriatr Soc 1997, 45:803-8.

23. Benetos A, Safar M, Rudnichi A, Smulyan H, Richard JL, Ducimetieere P, Guize L: Pulse pressure: a predictor of long-term cardiovascular mortality in a French male population. Hypertension 1997, 30: $1410-5$

24. Franklin SS, Khan SA, Wong ND, Larson MG, Levy D: Is pulse pressure useful in predicting risk for coronary heart Disease? The Framingham heart study. Circulation 1999, 100:354-60.

25. Randall OS, van den Bos GC, Westerhof N: Systemic compliance: does it play a role in the genesis of essential hypertension? Cardiovasc Res 1984, I 8:455-62.

26. Kass DA, Saeki A, Tunin RS, Recchia FA: Adverse influence of systemic vascular stiffening on cardiac dysfunction and adaptation to acute coronary occlusion. Circulation 1996, 93: I533-4I.

27. Kannel WB, Vasan RS, Levy D: Is the relation of systolic blood pressure to risk of cardiovascular disease continuous and graded, or are there critical values? Hypertension 2003, 42:453-6. Epub 2003 Sep 15

28. Gatzka CD, Cameron JD, Kingwell BA, Dart AM: Relation between coronary artery disease, aortic stiffness, and left ventricular structure in a population sample. Hypertension 1998, 32:575-8.

29. Herrington DM, Kesler K, Reiber JHC, Davis W, Brown VB, Helms R, Mallon SM, Raines J: Arterial compliance adds to conventional risk factors for prediction of angiograpic coronary arter disease. Am Heart ] 2003, 146:662-667.

30. Syeda B, Gottsauner-Wolf M, Denk S, Pichler P, Khorsand A, Glogar D: Arterial Compliance: a diagnositc marker for athreosclerotic plaque burden? Am J Hypertens 2003, 16:356-62.

31. Haluska BA, Matthys K, Fathi R, Rozis E, Carlier SG, Marwick TH: Influence of arterial compliance on presence and extent of ischaemia during stress echocardiography. Heart 2006, 92:40-3.

32. Kingwell BA: Large artery stiffness: implications for exercise capacity and cardiovascular risk. Clin Exp Pharmacol Physiol 2002. 29:2 I 4-7.

33. Kingwell BA, Waddell TK, Medley TL, Cameron JD, Dart AM: Large artery stiffness predicts ischaemic threshold in patients with coronary artery disease. I Am Coll Cardiol 2002, 40:773-9.

34. Lewington S, Clarke R, Qizilbash N Peto R, Collins R. Prospective Studies Collaboration. Age-specific relevance of usual blood pressure to vascular mortality: a meta-analysis of individual data for one million adults in 61 prospective studies. Lancet 2002, 360:1903-13.

35. Williams B, Lacy PS, Thom SM, Cruickshank K, Stanton A, Collier D, Hughes AD, Thurston H, O'Rourke M, CAFE Investigators; Anglo-Scandinavian Cardiac Outcomes Trial Investigators; CAFE Steering Committee and Writing Committee, et al: Differential impact of blood pressure-lowering drugs oncentral aortic pressure and clinical outcomes: principal results of the Conduit Artery Function Evaluation (CAFE) study. Circulation 2006, I I 3: I 2 I 3-25. Epub 2006 Feb 13

36. Marchais SJ, Guerin AP, Pannier BM, Levy BI, Safar ME, London GM Wave reflections and cardiac hypertrophy in chronic uremia. Influence of body size. Hypertension 1993, 22:876-83

37. Sharman JE, Fang ZY, Haluska B, Stowasser M, Prins JB, Marwick TH: Left Ventricular Mass in Patients with Type 2 Diabetes Mellitus is Independently Associated with Central but not Peripheral Pulse Pressure. Diabetes Care 2005, 28:937-939.

38. Breit SN, O'Rourke MF: Comparison of direct and indirect arterial pressure measurements in hospitalised patients. Aust NZ J Med 1974, 4:485-91

39. Watson S, Wenzel RR, di Matteo C, Meier B, Luscher TF: Accuracy of a new wrist cuff oscillometric blood pressure device: comparisons with intra-arterial and mercury manometer measurements. Am J Hypertens 1998, I I:1469-74. 